\title{
PRALIMAP: study protocol for a high school-based, factorial cluster randomised interventional trial of three overweight and obesity prevention strategies
}

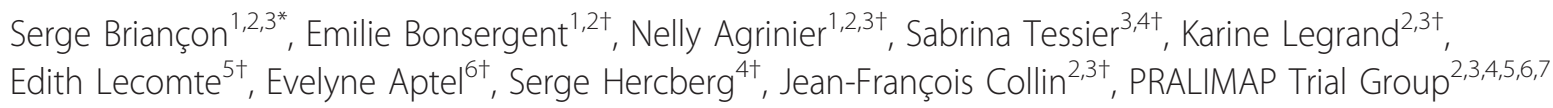

\begin{abstract}
Background: Given the increase in overweight and obesity prevalence in adolescents in the last decade, effective prevention strategies for these conditions in adolescents are urgently needed. The PRALIMAP (Promotion de I'ALImentation et de l'Activité Physique) trial aims to evaluate the effectiveness for these conditions of 3 health promotion strategies - educational, screening and environmental - applied singly or in combination in high schools over a 2-year intervention period.
\end{abstract}

Methods: PRALIMAP is a stratified $2 \times 2 \times 2$ factorial cluster randomised controlled trial including 24 state high schools in Lorraine, northeastern France, in 2 waves: 8 schools in 2006 (wave 1) and 16 in 2007 (wave 2). Students entering the selected high schools in the 4 academic years from 2006 to 2009 are eligible for data collection. Interventional strategies are organized over 2 academic years. The follow-up consists of 3 visits: at the entry of grade 10 (T0), grade 11 (T1) and grade 12 (T2). At T0, 5,458 (85.7\%) adolescents participated. The educational strategy consists of nutritional lessons, working groups and a final party. The screening strategy consists in detecting overweight/obesity and eating disorders in adolescents and proposing, if necessary, an adapted care management program of 7 group educational sessions. The environmental strategy consists in improving dietary and physical activity offerings in high schools and facilities, especially catering. The main outcomes are body size evolution over time, nutritional behaviour and knowledge, health and quality of life. An evaluation process documents how each intervention strategy is implemented in the schools and estimates the dose of the intervention, allowing for a per protocol analysis after the main intention-to-treat analysis.

Discussion: PRALIMAP aims at improving the prevention and management of overweight and obesity in adolescents by translating current evidence into public health practice. Particular attention is paid to clustering, multiple factorials and long-term duration to address common pitfalls in health promotion trials. The results should inform how best to implement, in a school environment, effective nutrition prevention programs targeting adolescents who are at a point their lives when they develop responsibilities and empowerment for health attitude behaviours.

Trial registration: This trial is registered at ClinicalTrials.gov under NCT00814554.

\section{Background}

Child and adolescence overweight and obesity prevalence has been increasing worldwide during the last decades. Overweight and obesity are considered the most widespread disorders in Europe, affecting, in 2002,

\footnotetext{
* Correspondence: serge.briancon@medecine.uhp-nancy.fr

+ Contributed equally

${ }^{1}$ Nancy-University, Paul Verlaine Metz University, Paris Descartes University, EA4360 Apemac, Nancy, France

Full list of author information is available at the end of the article
}

approximately 1 in 6 non-adults and in some parts of Europe up to 1 in 3 . Adolescents with a body mass index (BMI) equal to or greater than the 85th percentile are at increased risk of obesity in adulthood [1]. Thus, overweight and obesity prevention is an international public health priority requiring the implementation of effective interventions to produce changes in dietary and physical activity patterns in individuals. Two systematic reviews with inconsistent results have been published in

\section{Biomed Central}


this field $[2,3]$, and a recent commentary review explained the discrepant results [4] as being the heterogeneity of the studies in terms of target population, theoretical underpinning, study design and outcome measures.

Only one study in each review targeted adolescents, which confirmed that most programs and studies involve children. However, during adolescence, children are becoming independent and self-determined enough to establish eating habits and physical activity patterns. Besides communities and families, schools have been identified as key settings for public health strategies to lower or prevent the prevalence of overweight and obesity [5]. Fifteen-year-old adolescents spend more time at school than at any other setting outside of the home. The school food offerings potentially have a large impact on adolescents' eating habits because many students, especially those who board full-time or half-time, consume a substantial proportion of their total daily intake at school [6].

Many theoretical considerations underpin the choices, orientations, ways and means of implemented intervention strategies such as healthy eating, nutritional education, physical activity and environmental modifications. Stand-alone interventions or integrated interventions have discrepant effectiveness. The Ottawa charter provides a framework for health promotion actions around 5 means, of which 3 are particularly relevant in this field and context: develop personal skills, reorient health services and create supportive environments [7]. The contribution of each to overweight and obesity prevention alone and in combination has not been extensively explored. Such information would be of great interest for improving public health policies. In 2001 in France, the government set up a National Nutrition and Health Program ("Programme National Nutrition Santé", PNNS) to enhance the global health status of the population by improving nutrition. One of the main objectives was a $20 \%$ reduction in excess weight and obesity prevalence among adults and to stop the increase in obesity prevalence among children and adolescents [8]. Research results are awaited the plan renewal.

A powerful trial with an appropriate design - namely clustering and factorization - and with wide outcomes from knowledge to anthropometric measurements is needed to measure the long-term impact of such health promotion strategies among adolescents in schools. The present report describes the design, implementation and baseline characteristics of clusters and participants of the PRALIMAP (Promotion de l'ALImentation et de l'Activité Physique) trial, a $2 \times 2 \times 2$ factorial cluster, school-based randomised intervention trial testing the effectiveness of 3 overweight and obesity prevention strategies in adolescents.

\section{Objectives}

The main objective of the PRALIMAP trial is to evaluate the effectiveness of 3 public health interventional strategies - educational, screening, environmental applied alone or in combination over a 2-year intervention period to promote healthy dietary and physical activity for adolescents in high school. Adolescentcentred outcomes include nutritional knowledge, attitudes and behaviours; body size; and health-related quality of life (HRQoL).

The secondary objective is to evaluate the process and especially the feasibility of each strategy applied in the high school setting.

\section{Methods}

\section{Design of the PRALIMAP trial}

PRALIMAP is a stratified $2 \times 2 \times 2$ factorial cluster randomised controlled trial. The units of randomisation are state high schools; 24 high schools participated in the trial in 2 waves: 8 in 2006 (wave 1) and 16 in 2007 (wave 2). The interventional strategies are organized by 2 academic years, and follow-up consists of 3 visits.

The PRALIMAP trial has been approved by the French consultative committee for treatment of information in health research $\left(n^{\circ} 06.376\right)$ and the French data protection authority $\left(\mathrm{n}^{\circ} 906312\right)$. This trial is registered at ClinicalTrials.gov under NCT00814554 http://clinicaltrials.gov/ct2/show/NCT00814554.

\section{Study setting and high school recruitment}

In 2006, the Lorraine region, northeastern France, included 4 administrative departments, two of which being mainly rural area (Meuse and Vosges). It counted 2,34 billions inhabitants among whom 154,365 were adolescents aged of 14-18 years old with a higher proportion of boys $(51 \%, \mathrm{n}=79,246)$. Among these adolescents, 57\% $(\mathrm{n}=88,076)$ were attending 203 high schools of which 124 were state schools ( $n=80,935$ students) and 79 were independent schools ( $\mathrm{n}=7,141$ students). Of the state high schools, 46 were general and technological high schools, with 57,943 students: 14 were in Meurthe-et-Moselle, 1 in Meuse, 22 in Moselle and 9 in Vosges. The remaining 78 state high schools were oriented toward vocational secondary education (i.e., providing practice-oriented education for a specific occupation), with 22,992 students: 22 in Meurthe-et-Moselle, 7 in Meuse, 34 in Moselle and 15 in Vosges.

In 2007, 79,376 students were attending 122 state high schools in the 4 departments. Of the state high schools, 60 were general and technological high schools, with 57,284 students: 17 in Meurthe-et-Moselle, 4 in Meuse, 28 in Moselle and 11 in Vosges. The remaining 62 state high schools were vocational high schools, with 22,092 
students: 18 in Meurthe-et-Moselle, 4 in Meuse, 27 in Moselle and 13 in Vosges.

The only eligibility criteria for high school were to be a state administrative establishment $(n=124)$. The PRALIMAP trial group randomly selected 24 after stratification on department and type of education (general and technological or vocational) for participation in the PRALIMAP trial:

- 5 general and technological and 3 vocational high schools in Meurthe-et-Moselle

- 5 general and technological and 3 vocational high schools in Moselle

- 3 general and technological high schools and 1 vocational high school in Meuse

- 3 general and technological high schools and 1 vocational high school in Vosges

Every selected high school headmaster accepted to participate.

The stratification warranted a well-balanced representativeness on the two used criteria which are known to be associated to body size and nutritional knowledge, attitudes and behaviours.

\section{Randomisation and student recruitment}

The 24 high schools were assigned to receive the 3 strategies according to a $2 \times 2 \times 2$ factorial cluster (high school) randomisation as described in Figure 1. Stratification was on department and type of education. In total, 8 groups, with 3 high schools in each group, were assigned to receive the following interventions:

The 3 strategies (group A)

Educational and environmental strategies (group B)

Educational and screening strategies (group C)

Screening and environmental strategies (group E)

Educational strategy alone (group D)

Environment strategy alone (group F)

Screening strategy alone (group G)

No intervention (group $\mathrm{H}$ )

All students of the participating high schools who were registered in the grades targeted by the PRALIMAP trial were likely to be enrolled (Table 1 ).

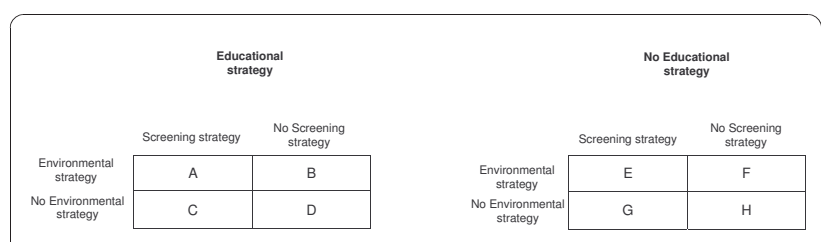

Figure 1 Randomisation in the PRALIMAP trial with a factorial plan $2 \times 2 \times 2$. A, B, C, D, E, F, G and $H$ : randomisation groups in the PRALIMAP trial.
Table 1 Number of new students entering the selected schools each year in the grade of interest

\begin{tabular}{ccccccc}
\hline & \multicolumn{5}{c}{ Academic year } \\
\hline Grade of interest & $\mathbf{2 0 0 6}$ & $\mathbf{2 0 0 7}$ & $\mathbf{2 0 0 8}$ & $\mathbf{2 0 0 9}$ & Total \\
\cline { 2 - 7 } & Grade 10 & $\underline{2,343}$ & 4,028 & & $\mathbf{6 , 3 7 1}$ \\
\cline { 2 - 7 } & Grade 11 & $\underline{312}$ & 547 & & $\mathbf{8 5 9}$ \\
\cline { 2 - 7 } & Grade 12 & & $\underline{207}$ & 331 & $\mathbf{5 3 8}$ \\
\hline & Total & $\mathbf{2 , 3 4 3}$ & $\mathbf{4 , 3 4 0}$ & $\mathbf{7 5 4}$ & 331 & $\mathbf{7 , 7 6 8}$
\end{tabular}

Wave 1 data are underlined, wave 2 data are italicized

Note: New students entering the selected high schools in the grade of interest for each of the 4 academic years beginning 2006 to 2009 are eligible for the data collection.

\section{Study Interventions (Table 2)}

Three prevention strategies are used. By "Educational strategy", we mean developing personal skills to adopt healthy behaviours in the field of nutrition (diet and physical activity) according to current guidelines $[7,8]$. By "Screening strategy", we mean measuring, detecting overweight/obesity and eating disorders, and proposing if necessary an adapted care management. By "Environmental strategy", we mean developing favourable and supportive environments for healthy behaviours targeting the catering supply of the school and the school policy.

The 3 strategies are implemented in high schools according to standard operating procedures. All activities are performed over the first 2 high school years (corresponding to grades 10 and 11 in the US educational system) between January and June. These strategies target individual nutritional behaviour by acting directly on student skills (educational strategy and screening strategy) or by changing the school environment (environmental strategy).

The educational and environmental strategies are managed by trained health education professionals external to the high schools, called PRALIMAP monitors, specifically recruited for the trial. The monitors clarify objectives to be reached, propose and initiate activities and accompany and support high school professionals. The screening strategy is managed by public health professionals of Nancy-University, high school nurses and practitioners and an external nutrition health network.

\section{Educational strategy}

This strategy includes 3 types of activities:

1. Nutrition and physical activity lectures, officially registered in the high school course offerings, are provided by high school teachers of Life Sciences and/or Physical Education. Teachers of other disciplines (e.g., librarian, communication, history and geography teachers) can be added according to school resources. The lectures represent 5 hours during the first high school year and 6 hours for the second high school year distributed according to availability of teachers. 
Table 2 Elements of the standard operating procedures for each of the $\mathbf{3}$ prevention strategies

\begin{tabular}{|c|c|c|}
\hline & First high school year (grade 10) & Second high school year (grade 11) \\
\hline $\begin{array}{l}\text { Educational } \\
\text { strategy }\end{array}$ & $\begin{array}{l}\text { - } 5 \text { hours of lectures on nutritional needs } \\
\cdot 2 \text { hours and personal work for groups on nutritional rhythms } \\
\text { or environment } \\
\text { - Organization of a 1-day or half-a-day PRALIMAP party }\end{array}$ & $\begin{array}{l}\text { - } 6 \text { hours of lectures on nutritional environment } \\
\text { - } 2 \text { hours and personal work for collective groups on influence of } \\
\text { medias, eco-citizenship, nutritional security measures and prices } \\
\text { of food and drink and physical activity } \\
\text { - Organization of a 1-day or half-a-day PRALIMAP party }\end{array}$ \\
\hline \multirow[t]{6}{*}{$\begin{array}{l}\text { Screening } \\
\text { strategy }\end{array}$} & $\begin{array}{l}\text { - } 2 \text { simultaneous measurements of height, weight and waist } \\
\text { circumference by nurses and completing of self-administered } \\
\text { questionnaire by student } \\
\text { - Calculation of body mass index (BMI) and of EAT-40 [17] and } \\
\text { HAD [21] scores } \\
\text { - Positive screening = overweight or obesity and high waist } \\
\text { circumference } \\
\text { - Notification of students with positive screening by nurses and } \\
\text { medical professional to explain results } \\
\text { - Proposition to participate to external healthcare network }\end{array}$ & $\begin{array}{l}\text { - } 2 \text { simultaneous measurements of height, weight and waist } \\
\text { circumference by nurses and completing of self-administered } \\
\text { questionnaire by student } \\
\text { - Calculation of body mass index (BMI) and of EAT-40[17] and } \\
\text { HAD [21] scores } \\
\text { - Positive screening = overweight or obesity and high waist } \\
\text { circumference } \\
\text { - Notification of students with positive screening by nurses and } \\
\text { medical professional to explain results } \\
\text { - Proposition to participate to external healthcare network }\end{array}$ \\
\hline & \multicolumn{2}{|c|}{$\begin{array}{l}\text { - Care management }=7 \text { group educational sessions during } 1.5 \text { hours supervised by external healthcare network specialized for } \\
\text { nutrition: }\end{array}$} \\
\hline & \multirow{4}{*}{\multicolumn{2}{|c|}{$\begin{array}{l}>\text { A first session to inform and answer questions about nutrition and weight supervised by a physician and a dietician } \\
>\text { Two sessions on food practices supervised by a dietician and a psychologist } \\
>\text { Two sessions on physical activities practices supervised by a sports educator and a psychologist } \\
>\text { Two sessions on nutritional changes led by a dietician and supervised by all professionals }\end{array}$}} \\
\hline & & \\
\hline & & \\
\hline & & \\
\hline \multirow{4}{*}{$\begin{array}{c}\text { Environmental } \\
\text { strategy }\end{array}$} & \multicolumn{2}{|c|}{ - Inventory of sports and collective catering features and facilities as well as available activities through an environmental survey } \\
\hline & \multicolumn{2}{|c|}{ - Improvement of environmental characteristics adhering to the PNNS [8] guidelines standing. } \\
\hline & \multicolumn{2}{|c|}{ - Implementation of new features and activities to improve nutritional environment. } \\
\hline & \multicolumn{2}{|c|}{ - Organization of a 1-day or half-a-day PRALIMAP party } \\
\hline
\end{tabular}

2. Students perform collaborative work with partial supervision by teachers and a PRALIMAP monitor. Students are allowed to discover, exchange and find their own answers to a nutritional rhythm and environment and the influence of environmental pressure on nutritional individual choices (e.g., influence of the media, eco-citizenship, cost) during 2 hours during the first and second high school year.

3. A 1-day or half-a-day PRALIMAP party is organized during the last trimester of every school year to reinforce the learned knowledge about healthy food choices and to be physically active in an atmosphere of conviviality, pleasure and friendship. Several activities are organized (e.g., fun physical activities, games, tests, conferences, food and drink tasting), and the production of collaborative works previously described are appreciated according to the availability of high school staff. All high school professionals and all students are invited to participate in the event.

\section{Screening strategy}

Weight, height and waist circumference of students are measured twice in a single session by high school nurses in the nurse's office, and the Eating Attitudes Test 40 (EAT-40) and Hospital Anxiety and Depression (HAD) questionnaires are completed. All these data are part of the follow-up visit data collection.
The body weight of students wearing underwear is measured with an accuracy of $0.05 \mathrm{~kg}$ by use of a calibrated electronic scale (SECA ${ }^{\oplus}$ : model number 873 1321009). The body height of students not wearing shoes is measured by a stadiometer $\left(\mathrm{SECA}^{\circ}\right.$ : reference SECA 214 SEC 01) to the nearest $0.1 \mathrm{~cm}$. The body mass index (BMI) is calculated as weight/height ${ }^{2}$ from the mean of the above 2 measurements. We used the International Obesity Taskforce (IOTF) age- and sexspecific cut-off values for BMI for thinness grades 1, 2 and 3 [9], overweight and obesity [10], with dataset-specific centiles linked to adult cut-off values. Waist circumference is measured with use of a non-elastic flexible tape $\left(\mathrm{SECA}^{\oplus}\right.$ : reference $200 \mathrm{SEC} \mathrm{01)}$ at the level of the bellybutton to the nearest $0.1 \mathrm{~cm}$ with the subject in a standing position. We use the McCarthy [11] ageand sex-specific cut-off values to define high waist circumference using dataset-specific centiles linked to adult cut-off values. A positive screening is defined by an overweight or obesity according to BMI and high waist circumference.

An EAT-40 score $\geq 30$ (on a $0-120$ scale) is used as a cut-off value to identify students suspected of having eating disorders. HAD scores $\geq 11$ (on a $0-21$ scale) is used as a cut-off value to identify students suspected of having anxiety and/or depression. 
Nurses notify students with positive screening orally and in writing, explain the consequences of overweight and the importance of adapted care management, and give them letters containing the screening results, including EAT-40 and HAD scores, one for their parents and one for their general practitioner. As recommended by Nihiser et al. [12], the letter to parents typically includes the child's BMI-for-age percentile, an explanation of the results and recommendations for care management. The adapted care management consists of 7 group educational sessions, offered for 1.5 hours by physicians, dieticians, sport educators and psychologists. These sessions are implemented outside of the high school by an external healthcare network specialized in nutrition or inside the high school by a mobile team if a network is not available in the surrounding territory of the high school. These sessions are funded by the regional health insurance system.

\section{Environmental strategy}

This strategy aims at extending the range of students' nutritional choices and consists in increasing the availability of fruits, vegetables, bread and dairy products, water and physical activity.

First, an environmental survey compiles an inventory of activities and facilities for sports and catering features and facilities at the high school. Second, the environmental characteristics fitting the PNNS guidelines is improved through activities such as presenting a menu with the food group colours and signs for water distribution, and producing information support on available physical activities. Third, a project committee consisting of high school professionals, including the school headmaster, and the PRALIMAP monitor is in charge of implementing new features and activities to improve the nutritional environment. New projects and features can be funded by the regional council of the academic program. The final activity of the environmental strategy is the PRALIMAP party as described for the educational strategy except that students do not participate to the organization and have no collaborative works to present.

\section{Outcomes and process data}

Outcomes and process data are collected. The outcomes include anthropometric data, nutritional attitudes and behaviours, and perceived health and quality of life. The main endpoint of the PRALIMAP trial is the evolution of overweight and obesity prevalence over the 2 intervention years.

Process data include quantitative and qualitative measures of participation and implementation of the 3 strategies according to all the stakeholders.

\section{Outcomes}

The outcomes data sources are the Board of Education database, self-administered questionnaires, and anthropometric measures.
Data collection The 3 follow-up visits (T0, T1, and T2) are carried out at the beginning of the 3 academic years (grades 10, 11 and 12) for general and technological high schools and at the beginning of the 2 academic years and at the end of the second academic year for vocational high schools (Figure 2).

Every academic year, an information letter is sent to the student's parents. Parents must sign a written refusal to collect data for their children. In the high school, students are also given written and oral information. The PRALIMAP monitor explains the purpose of the measurements, reassures students about the confidential nature of data, answers any queries and confirms the right not to participate.

Students entering the selected high schools in the grade of interest in each of the 4 academic years from 2006 to 2009 are eligible for data collection (Figure 2 and Table 1). Students not fluent in reading or writing French or with delayed entry in the high school grade are ineligible.

At each follow-up visit, data on sociodemographic characteristics, nutritional attitudes and behaviours, and perceived health and quality of life are collected by selfadministered questionnaires completed in the classroom and merged in a unique report form; body size is measured by trained nurses in the high school nurse's office. Nonattending students are contacted once or twice as necessary for data collection.

Sociodemographic characteristics Sociodemographic characteristics are compiled from the Board of Education database and completed self-administered questionnaires. Data are collected on date of birth, gender, grade, social and professional class of the family head at entry of the student into grade 10 (in 5 groups according to the definition of the French national institute of statistic and economical studies [INSEE]), school boarding status (non-boarder, half-boarder or full boarder), residence (type of residential area, house type, number of people in the home), parents' occupations, adolescent's perception

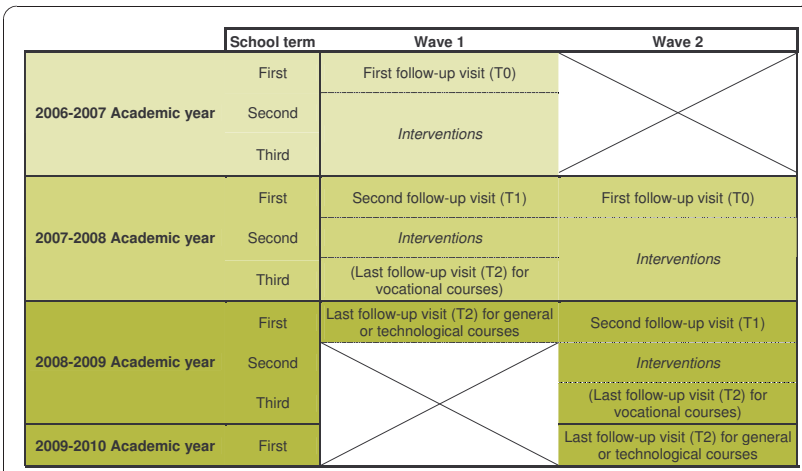

Figure 2 PRALIMAP trial schedule. 
of their parents' weight status and physical activity practice, and family income.

Anthropometry This process involves measuring students' body size according to weight, height, and waist circumference during the follow-up visits and calculating BMI. The international BMI cut-off values [10] are used. The 97th percentile of the Rolland-Cachera curves are also considered [13]. High waist circumference is defined according to McCarthy [11] and/or Katzmarzyk and Lean [14,15]. Overweight and obesity are defined according to BMI cut-off values alone or in combination with waist circumference values. The operating procedures are detailed in the "Screening strategy" paragraph.

Nutritional knowledge, attitudes and behaviours Nutritional knowledge level is obtained by a quiz on dietary guidelines, physical activity, and health and nutrition relationship, for a score ranging from 0 to 100 . Attitudes and behaviours are measured with the specifically designed Boire Manger Bouger (BMB; "Drinking, Eating, Moving") questionnaire. Satisfaction with food and physical activity and ability to follow guidelines for fruits and vegetables, dairy products, starchy food, drinks, sugary foods, number of meals and physical activity are explored. The environmental conditions of meals are also investigated.

Physical activity is measured by the International Physical Activity Questionnaire (IPAQ) [16]. The IPAQ assesses the frequency (days per week) and duration (minutes) of sitting and walking and of moderate and vigorous physical activity during the previous 7 days. Physical activity level is thus defined as low, moderate or high (the high level corresponds to nutritional guidelines).

Health The EAT-40 [17], a validated and widely used questionnaire, screens for anorexic and bulimia symptoms. It is a self-reporting questionnaire with responses on a 6-point Likert scale ranging from 0, never, to 6, always. Four dimensions are explored: dieting, bulimia/ food preoccupation, oral control and overall eating disorder [18]. Scores are estimated and the cut-off values used are those recommended by the authors.

The HAD $[19,20]$ screens for depression and anxiety with 14 items on a 4-point Likert scale (range $0-3$ ). The psychometric properties in the general population are acceptable [21]. The total score is the sum of the scores on the 14 items, and for each of the 2 subscales, the score is the sum of the scores on the respective 7 items.

The Duke Health profile [22,23], a 17-item generic self-reporting questionnaire explores perceived health and HRQoL with 10 dimensions; the physical, mental, and social dimensions are commonly used. High scores on the 0-100 scale indicate good HRQoL.

To facilitate interpretation, all scores are normalized to a $0-100$ scale.

\section{Process}

Extensive process evaluation is considered a main part of the trial design. This evaluation aims to document how schools assigned to an interventional strategy implement it, and if control schools for this strategy implement interventions related to the theme of this strategy (e.g., environmental interventions implemented in a school that is a control for the environmental strategy). Other main aims are to collect information on the provision and receipt of the 3 nutritional interventions, determine the extent of possible contamination between schools, and report on the experience and impact of the PRALIMAP trial. Thus 2 domains - implementation and participation - are explored according to quality and quantity and from 4 points of view: students, PRALIMAP monitors, and school professionals as receivers of information from the PRALIMAP team and as providers of the intervention to students.

The process data sources are observation, stakeholders' interviews, and adolescent self-administered questionnaires.

Observation Members of the research team observe the key processes in the implementation of interventional strategies in every high school and document the processes in activity reports. This observation includes regular meetings with high school professionals and teachers and an annual environmental survey. Meetings are organized once a month, are conducted by the PRALIMAP monitor, and aim to accompany and follow the performance of activities and to uphold the dynamics of the school's investment in the process. As described for the environmental strategy, the PRALIMAP monitor carries out an environmental survey of the headmaster, the financial administrator and the physical education teachers, whatever the strategy assigned to the school, at the beginning of every academic year.

Stakeholders' interview A collective interview (focus group) is carried out with staff responsible for interventional strategies (high school professionals, head teachers) at the end of the 2 intervention years. It is lead by the process experts and psychologists of the PRALIMAP research team. Every PRALIMAP monitor is independently interviewed by use of a semi-structured interview guide by the PRALIMAP process evaluation lead at this time. The aim is to gather information about the content, delivery and stakeholders' appreciation of the intervention strategies over the 2 years (i.e., what was done, what stakeholders liked and disliked, the pros and cons of the interventions, their degree of satisfaction with the program, their appraisal of the benefit for students and recommendations for their own school and others). For the focus group, a full narrative description includes who was present, what was said, interactions between participants, the atmosphere, and 
the occurrence of significant events such as participants entering or leaving.

Student appreciation A year-specific appreciation questionnaire is included at the T1 and T2 student report form. The survey aims to gain insight into students' perception and evaluation of the PRALIMAP trial (i.e., the school nutritional offerings, interactions with health and high school professionals, PRALIMAP activities participation, what they liked and disliked, how they perceived and incorporated interventional strategies and PRALIMAP as a whole).

\section{Data management and quality control}

A Microsoft Access-based information system was developed to warehouse data (Microsoft Access 2003 v11.5614.6568, Seattle, WA, USA). At baseline, 15 keyboarders in 2006 and 18 in 2007 entered 18,105 and 28,836 data elements, respectively. The mean error rate was 30 per 10,000 data elements.

\section{Sample size}

A total of 6,500 students were expected to attend grade 10 in the 24 high schools participating in the PRALIMAP trial. We anticipated approximately 5,590 participants on the basis of an approximately $86 \%$ mean participation rate of students in other nutritional studies [24-26]. Finally, from a sample size of 5,475, an average cluster size of 228 students and an anticipated intraclass correlation coefficient (ICC) of 0.005 , we estimated a difference of approximately $4 \%$ in prevalence of overweight/obesity between the intervention and non-intervention arms at the end of PRALIMAP trial, assuming an alpha risk of $5 \%$ and a power of $80 \%$. Power is assumed to be higher for other endpoints, namely, nutritional knowledge, attitudes and behaviours.

\section{Planned Analysis}

The main judgment criteria consist of body size indicators: overall evolution of overweight and obesity prevalence, and among students with normal body size at trial entry, mean BMI evolution, proportion of students whose BMI evolution curve from baseline to the end of follow-up deviated from the IOTF and French norms for BMI between 16 and 18 years of age. Secondary judgment criteria refer to nutritional knowledge attitudes and behaviours and perceived health and quality of life, namely, the evolution in proportion of adolescents following nutritional guidelines and in mean nutritional knowledge score, the proportion of adolescents with eating disorders and high anxiety or depression scores, and finally Duke physical, mental and social dimensions scores.

Basic descriptive statistics were used to characterize the baseline participant population and interventions at both the participant and cluster levels. To produce accurate estimates of the used indicators in the Lorraine general population attending high schools, students' data were weighted by the product inverse of their high school probability to be included and their probability to participate. Intra-cluster similarity was analyzed by the ICC.

Students leaving high school, as well as students participating in the PRALIMAP over the intervention period will be described by a flow chart according to the CONSORT statement adapted to cluster randomised trials $[27,28]$ and analyzed for possible selection bias.

Both cross-sectional and longitudinal analyses with cluster-specific methods are planned. General Estimating Equations (GEE) models will be used to take in account the hierarchical and longitudinal nature of the data. All analyses are planned at the individual student level on an intention-to-treat basis. Given the complexity of the analysis, details will be described more completely in the future.

The dose of intervention students receive will be estimated by the evaluation process in terms of a score developed by experts and will be taken into account on a per protocol analysis. Details of this analysis will be presented elsewhere.

SAS can accommodate the factorial clustered design and will be used for analysis (SASTM v9.2, SAS Inst., Cary, NC, USA).

\section{Inclusion data}

The flow diagram (Figure 3) presents the processing of clusters and students through the initial phases of the PRAMILAP.

At cluster enrolment, the mean overall high school size was 812 students (range 283-1,893 students), and $29 \%$ had more than 1,000 students. The mean grade 10 size was 265.5 students (72-568). The mean grade 10 participants cluster size was 227.4 students (57-478). Thus, among the 6,371 grade 10 students, 5,458 (85.7\%) underwent at least one baseline measurement, without any difference in participation in anthropometric and self-administered measurements. High school participation rates highly differed (from $72.0 \%$ to $99.1 \%$ ) and were higher in general and technological than vocational high schools $(86.6 \%$ vs $80.9 \%, \mathrm{p}=<0.0001)$ and in the rural administrative department of Vosges than in the other 3 departments $(89.3 \%$ vs $85.1 \%, p=0.0014)$. Finally, participation rates differed significantly but only slightly between strategy and control schools: educational strategy $(86.9 \%$ vs $84.3 \%, \mathrm{p}=0.003)$, screening strategy $(84.2 \%$ vs $87.1 \%, \mathrm{p}=0.001)$ and for environmental strategy $(84.6 \%$ vs $86.7 \%, \mathrm{p}=0.013)$.

As compared with participants, non-participants were significantly older $(\mathrm{p}=<0.0001)$ and more often had 


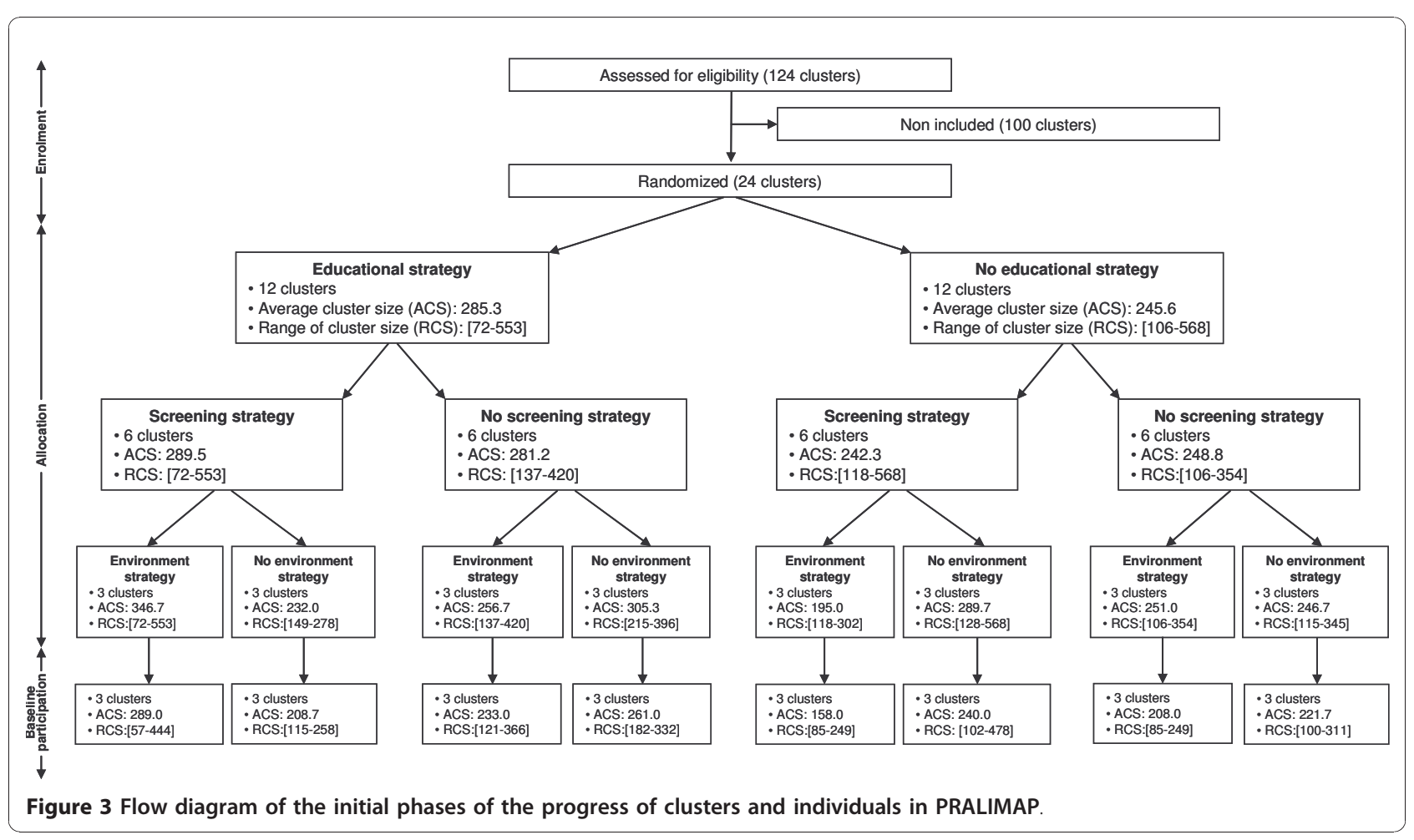

unemployed parents ( $\mathrm{p}=0.0143)$ and school backwardness $(\mathrm{p}<0.0001)$. Boys and girls participated equally. Adolescents' baseline characteristics, overall and by strategy, are presented in Table 3, 4 and 5 and were similar to the French grade 10 population [29]. Students were in the expected age range, with more than $70 \%$ aged 15 years old. In total, 36\%, 70\%, 53\% and $50.1 \%$ of students had school backwardness, were in grade 10 in a general and technological school, were girls and the family head was employed, respectively, as compared with $20 \%, 67 \%, 54 \%$ and $41 \%$, respectively, in the French grade 10 population [29].

Nutritional guidelines the most likely to be improved by interventions are those for fruits and vegetables (13.5\%), limiting nibbling $(29.1 \%)$, sugary foods $(34.1 \%)$, dairy products $(42.0 \%)$ and physical activity (46.6\%), as well as the number of nutritional guidelines followed $(<27 \%$ did not follow at least two-thirds of the nutritional guidelines). The mean nutritional knowledge score was only about half the total score and suggests an opportunity for improvement, especially for the educational strategy.

Higher ICCs (>0.100) were observed for age, kind of course (general and technological or vocational), type of schooling, residence (rural or urban), knowledge score and waist circumference (see additional file 1: ICC 1 , for overall and by strategy). Stratification increased the power greatly for all outcomes except gender, kind of course, residence and waist circumference (see additional file 2: ICC 2, for overall and by strategy).
Most of the students were half-time boarders $(\mathrm{n}=$ $3,766,68.2 \%)$ and more often lived in urban areas $(\mathrm{n}=$ $2,663,47.0 \%) ; 50.1 \%$ had parents who worked and $59.8 \%$ declared a high family income.

At baseline, $14.9 \%$ of adolescents were overweight ( $\mathrm{n}=$ $792)$ and $4.6 \%$ were obese $(n=215)$. The mean BMI was $21.1 \mathrm{~kg} / \mathrm{m}^{2}$ (standard error of mean $(\mathrm{SEM}=0.1$ ), and was higher in girls than in boys (respectively $21.8 \mathrm{~kg} / \mathrm{m}^{2}$ $(\mathrm{SEM}=0.1)$ vs $21.6(\mathrm{SEM}=0.1))$ but the sexes did not differ in overweight and obese proportion. Concerning family nutritional environment, $54.9 \%$ of students declared a low parent physical activity, and 39.1\% reported that their parents were overweight. Some students were at high risk of psychological troubles: $8.8 \%$ of students were at high risk of eating disorders, $23.3 \%$ anxiety and $3.2 \%$ depression.

\section{Discussion}

The need for randomised trials of complex interventions such as health promotion are high, but such trials are a relatively new phenomenon $[2,3]$, and their role is still not self-evident in public health nutrition research. Clustering, multiple factorial and long-term duration are particularly suited for health promotion trials intended to provide high-quality evidence to support public health policy [30]. Such trials allow for implementing interventions in real conditions within appropriately diverse populations from heterogeneous settings and reporting on a broad range of health outcomes. 
Table 3 Baseline sociodemographic characteristics of students, overall and by assigned strategy

\begin{tabular}{|c|c|c|c|c|c|c|c|}
\hline & \multirow[t]{2}{*}{ Overall" } & \multicolumn{2}{|r|}{$\begin{array}{r}\text { Educational } \\
\text { strategy }\end{array}$} & \multicolumn{2}{|r|}{$\begin{array}{r}\text { Screening } \\
\text { strategy }\end{array}$} & \multicolumn{2}{|c|}{$\begin{array}{r}\text { Environmental } \\
\text { strategy }\end{array}$} \\
\hline & & No & Yes & No & Yes & No & Yes \\
\hline & $N=5,458$ & $N=2,483$ & $N=2,975$ & $N=2,771$ & $N=2,687$ & $N=2,794$ & $N=2,664$ \\
\hline & $\%$ & $\%$ & $\%$ & $\%$ & $\%$ & $\%$ & $\%$ \\
\hline Mean age (years) & $15.8^{*}$ & $15.7^{¥}$ & $15.7^{¥}$ & $15.7^{\#}$ & $15.7^{¥}$ & $15.7^{¥}$ & $15.7^{*}$ \\
\hline Gender (\% girls) & 52.9 & 56.8 & 53.6 & 56.5 & 53.6 & 54.8 & 55.4 \\
\hline General and technological course & 69.7 & 78.6 & 83.3 & 77.9 & 84.5 & 78.9 & 83.5 \\
\hline \multicolumn{8}{|l|}{ School boarding status } \\
\hline Non-boarder & 22.6 & 21.9 & 21.4 & 21.1 & 22.1 & 24.8 & 18.2 \\
\hline Half-boarder & 68.2 & 70.4 & 68.4 & 68.5 & 70.1 & 66.1 & 72.7 \\
\hline Full Boarder & 9.2 & 7.7 & 10.3 & 10.4 & 7.8 & 9.1 & 9.1 \\
\hline \multicolumn{8}{|l|}{ Schooling } \\
\hline Classic & 61.4 & 64.9 & 67.2 & 65.8 & 66.6 & 65.2 & 67.1 \\
\hline Advance placement at school & 2.1 & 2.2 & 2.8 & 2.3 & 2.8 & 2.6 & 2.5 \\
\hline Late placement at school & 36.4 & 32.9 & 29.9 & 31.9 & 30.7 & 32.2 & 30.4 \\
\hline Residence (Rural) & 47.0 & 47.1 & 50.3 & 54.3 & 43.3 & 46.2 & 51.6 \\
\hline \multicolumn{8}{|l|}{ Social and professional class of the family head } \\
\hline Farmers, shopkeepers, craftsmen, managers & 7.3 & 7.8 & 8.3 & 8.6 & 7.6 & 7.2 & 9.0 \\
\hline Executives & 12.6 & 14.4 & 13.7 & 11.1 & 17.0 & 15.8 & 12.1 \\
\hline Intermediate jobs & 18.5 & 18.5 & 21.0 & 17.7 & 22.1 & 20.9 & 18.8 \\
\hline Employees, workers & 50.1 & 50.4 & 46.2 & 52.3 & 43.9 & 46.4 & 49.9 \\
\hline Inactive (unemployed, retired) & 11.4 & 8.9 & 10.8 & 10.4 & 9.5 & 9.7 & 10.2 \\
\hline \multicolumn{8}{|l|}{ Parents occupation $* *$} \\
\hline Neither of the 2 parents works & 7.0 & 5.2 & 6.5 & 6.6 & 5.1 & 5.0 & 6.8 \\
\hline One of the 2 parents works & 31.3 & 29.8 & 30.2 & 31.0 & 29.0 & 28.8 & 31.2 \\
\hline The 2 parents work & 61.7 & 65.1 & 63.4 & 62.4 & 65.9 & 66.2 & 62.0 \\
\hline \multicolumn{8}{|l|}{ Family income level ${ }^{* *}$} \\
\hline Low & 6.9 & 6.3 & 6.7 & 7.5 & 5.5 & 6.0 & 7.0 \\
\hline Average & 33.3 & 33.6 & 34.4 & 33.9 & 34.2 & 34.4 & 33.7 \\
\hline High & 59.8 & 60.1 & 58.9 & 58.6 & 60.3 & 59.6 & 59.3 \\
\hline \multicolumn{8}{|l|}{ Parental physical activity level ${ }^{* *}$} \\
\hline Low & 54.9 & 53.1 & 53.1 & 54.3 & 51.8 & 52.7 & 53.4 \\
\hline Moderate & 3.8 & 4.4 & 3.3 & 4.2 & 3.4 & 3.8 & 3.8 \\
\hline High & 41.2 & 42.5 & 43.6 & 41.5 & 44.7 & 43.4 & 42.8 \\
\hline Parents considered overweight ${ }^{* *}$ & 39.1 & 40.0 & 40.2 & 40.1 & 40.2 & 40.4 & 39.8 \\
\hline
\end{tabular}

I Overall baseline characteristic parameters are estimated according to stratification and cluster design

$¥$ Standard Deviation $=0.7$

* Standard Error of the Mean $=0.02$

** Declared by adolescents

Cluster randomised trials are a common and necessary design for assessing community interventions, especially when they involve environmental actions and rely on interactions between subjects. This type of trial has methodological difficulties [31,32] and is still not well reported [33]. We paid attention to the building of clusters for representativeness at the regional level and a minimal clustering effect through stratification; to the sample size calculation, taking into account several ICC estimates for each outcome [31]; and finally to the reporting process according to the CONSORT statement extended for cluster randomized trials [28]. A limitation of clustered randomised trials is that the interventions cannot be blinded. This potential bias is minimized since we ensured randomisation by high school, that only school nurses are responsible for anthropometric measures, and the factorial plan created a combination of interventions.

The PRALIMAP trial incorporates a rare $2 \times 2 \times 2$ factorial cluster randomised design. The design was selected to evaluate all 3 strategies and their potential synergy. Factorial designs have been used in individual 
Table 4 Baseline nutritional attitudes and behaviours of students, overall and by the assigned strategy

\begin{tabular}{|c|c|c|c|c|c|c|c|c|c|c|c|c|c|c|}
\hline & \multirow{2}{*}{\multicolumn{2}{|c|}{ Overall" }} & \multicolumn{4}{|c|}{$\begin{array}{r}\text { Educational } \\
\text { strategy }\end{array}$} & \multicolumn{4}{|c|}{$\begin{array}{r}\text { Screening } \\
\text { strategy }\end{array}$} & \multicolumn{4}{|c|}{$\begin{array}{r}\text { Environmental } \\
\text { strategy }\end{array}$} \\
\hline & & & & No & & Yes & & No & & Yes & & No & & Yes \\
\hline & \multicolumn{2}{|c|}{$N=5,458$} & \multicolumn{2}{|c|}{$\mathrm{N}=2,483$} & \multicolumn{2}{|c|}{$\mathrm{N}=2,975$} & \multicolumn{2}{|c|}{$\mathrm{N}=2,771$} & \multicolumn{2}{|c|}{$N=2,687$} & \multicolumn{2}{|c|}{$N=2,794$} & \multicolumn{2}{|c|}{$N=2,66$} \\
\hline & $\begin{array}{r}\% / \\
\text { mean* }\end{array}$ & $\mathrm{SEM}^{* *}$ & $\begin{array}{r}\% / \\
\text { mean* }\end{array}$ & $\underset{¥}{\mathrm{SD}}$ & $\begin{array}{r}\% / \\
\text { mean* }\end{array}$ & $\mathrm{SD}_{¥}$ & $\begin{array}{r}\% / \\
\text { mean* }\end{array}$ & $\underset{¥}{\mathrm{SD}}$ & $\begin{array}{r}\% / \\
\text { mean* }\end{array}$ & $\mathrm{SD}_{\sharp}$ & $\begin{array}{r}\% / \\
\text { mean* }\end{array}$ & $\underset{¥}{S D}$ & $\begin{array}{r}\% / \\
\text { mean* }\end{array}$ & $\mathrm{SD}_{\sharp}$ \\
\hline Knowledge score $(0-100)$ & 50.9 & 0.5 & 51.9 & 9.1 & 51.2 & 9.0 & 51.6 & 9.0 & 51.4 & 9.1 & 51.7 & 9.1 & 51.3 & 9.0 \\
\hline \multicolumn{15}{|l|}{ Dietary guidelines followed } \\
\hline Fruits and vegetables $\left(\geq 5^{\#}\right)$ & 13.0 & & 12.3 & & 14.5 & & 13.0 & & 14.0 & & 13.4 & & 13.6 & \\
\hline Meats, eggs and fishes $\left(1-2^{\#}\right)$ & 94.7 & & 94.7 & & 95.1 & & 95.0 & & 94.8 & & 95.2 & & 94.6 & \\
\hline Sugary foods $\left(2-3^{\#}\right)$ & 33.3 & & 35.2 & & 33.1 & & 32.6 & & 35.5 & & 33.4 & & 34.7 & \\
\hline Dairy product $\left(3-4^{\#}\right)$ & 40.8 & & 40.3 & & 43.3 & & 42.1 & & 41.8 & & 41.6 & & 42.3 & \\
\hline Starchy foods (3 to $\left.6^{\#}\right)$ & 69.1 & & 70.7 & & 71.0 & & 71.1 & & 70.7 & & 71.6 & & 70.1 & \\
\hline Drinks $\left(\geq 5^{\#}\right)$ & 85.9 & & 85.5 & & 86,0 & & 85.6 & & 85.7 & & 84.9 & & 86.7 & \\
\hline Number of meals per week (21-28) & 61.1 & & 62.6 & & 64.1 & & 64.1 & & 62.7 & & 64.0 & & 62.8 & \\
\hline Nibbling & 70.9 & & 70.0 & & 68.2 & & 69.3 & & 68.8 & & 67.5 & & 70.7 & \\
\hline Physical activities guidelines followed & 47.1 & & 45.6 & & 47.3 & & 45.9 & & 47.2 & & 46.3 & & 46.8 & \\
\hline $\begin{array}{l}\text { Number of nutritional guidelines } \\
\text { followed }\end{array}$ & 4.3 & 0.04 & 4.3 & 1.3 & 4.4 & 1.3 & 4.3 & 1.3 & 4.3 & 1.3 & 4.4 & 1.3 & 4.3 & 1.3 \\
\hline$\leq 2$ & 9.3 & & 8.1 & & 8.2 & & 7.9 & & 8.5 & & 8.1 & & 8.3 & \\
\hline 3 & 18.3 & & 18.1 & & 17.2 & & 17.4 & & 17.7 & & 16.8 & & 18.4 & \\
\hline 4 & 30.0 & & 30.6 & & 27.9 & & 30.1 & & 28.2 & & 30.1 & & 28.1 & \\
\hline 5 & 25.4 & & 26.0 & & 26.5 & & 26.2 & & 26.3 & & 25.8 & & 26.7 & \\
\hline 6 & 12.7 & & 12.6 & & 15.1 & & 14.1 & & 13.8 & & 14.4 & & 13.5 & \\
\hline$\geq 7$ & 4.2 & & 4.6 & & 5.2 & & 4.4 & & 5.5 & & 4.8 & & 5.1 & \\
\hline
\end{tabular}

I Overall baseline characteristic parameters are estimated according to stratification and cluster design

* Data are mean when SD is displayed or percentages

** Standard Error of the Mean

$¥$ Standard Deviation

\# Number of daily servings recommended by nutritional guidelines

randomised trials, but combined with clustering, fewer than 10 were $2 \times 2$ designs, and to our knowledge, only 1 was a $2 \times 2 \times 2$ design [34].

The PRALIMAP trial duration is in line with the Sharma et al. recommendations to provide interventions longer than 6 months $[35,36]$. The PRALIMAP interventions spread out over 24 months allows for drawing conclusions that are sustainable in the long run.

High schools were included in 2 waves, of 8 and 16 schools each. We chose this format because we were unable to implement the interventions and the measurements at the same time in the 24 schools spread over a $23,547-\mathrm{km}^{2}$ area and including more than 2,000 professionals to be informed and trained. This design appears to be superior to an experimental pilot site, through the dynamics created between the 2 waves of high schools and the ability to respect the randomisation plan (balance between strategies according to stratification criteria). A wave effect will be looked for and, if needed, taken into account in the analysis.

We chose adolescents as the target for the PRALIMAP intervention. During adolescence, individuals develop responsibility for health-related behaviours and attitudes that affect their future [37,38]. Moreover, eating habits initiated during this time are long-lasting [39]. Eventually, a strategy based on fostering personal responsibility, cognitive self-regulation and competence could be effective in improving healthful eating and physical activity behaviours among middle school children [40]. We did not involve parents in the intervention because adolescents' increasing independence around food choice is described as an act of parental defiance and peer solidarity [41]. Adolescents resolve the conflict between their need for autonomy over their food choices and the needs of others in the family by making their own meals, eating out, eating what is served, and negotiating to have their own and 
Table 5 Baseline health and anthropometric characteristics of students, overall and by the assigned strategy

\begin{tabular}{|c|c|c|c|c|c|c|c|c|c|c|c|c|c|c|}
\hline & & & \multicolumn{4}{|c|}{$\begin{array}{r}\text { Educational } \\
\text { strategy }\end{array}$} & \multicolumn{4}{|c|}{$\begin{array}{r}\text { Screening } \\
\text { strategy }\end{array}$} & \multicolumn{4}{|c|}{$\begin{array}{r}\text { Environmental } \\
\text { strategy }\end{array}$} \\
\hline & \multirow{2}{*}{\multicolumn{2}{|c|}{$\begin{array}{c}\text { Overall }^{\text {श }} \\
\mathrm{N}=5,458\end{array}$}} & & No & & Yes & & No & & Yes & & No & & Yes \\
\hline & & & $N=2$ & 2,483 & $\mathrm{~N}=2$ & 2,975 & $\mathrm{~N}=2$ & 2,771 & $\mathrm{~N}=2$ & 2,687 & $\mathrm{~N}=2$ & 2,794 & $\mathrm{~N}=2$ & 2,664 \\
\hline & $\begin{array}{r}\% / \\
\text { mean* }^{*}\end{array}$ & SEM $^{* *}$ & $\begin{array}{r}\% / \\
\text { mean* }^{*}\end{array}$ & $\mathrm{SD}^{*}$ & $\begin{array}{r}\% / \\
\text { mean* }^{*}\end{array}$ & $\mathrm{SD}^{*}$ & $\begin{array}{r}\% / \\
\text { mean* }\end{array}$ & $\mathrm{SD}^{*}$ & $\begin{array}{r}\% / \\
\text { mean* }\end{array}$ & $\mathrm{SD}^{*}$ & $\begin{array}{r}\% / \\
\text { mean* }^{*}\end{array}$ & $\mathrm{SD}^{*}$ & $\begin{array}{r}\% / \\
\text { mean* }\end{array}$ & $\mathrm{SD}^{*}$ \\
\hline Body mass index $\left(\mathrm{kg} / \mathrm{m}^{2}\right)$ & 21.7 & 0.1 & 21.5 & $\overline{3.3}$ & 21.7 & 3.6 & 21.7 & 3.7 & 21.5 & 3.3 & 21.6 & 3.6 & 21.6 & 3.4 \\
\hline \multicolumn{15}{|l|}{ Body size (IOTF classification) } \\
\hline Thinness Grade 3 & 0.2 & & 0.1 & & 0.3 & & 0.3 & & 0.2 & & 0.1 & & 0.4 & \\
\hline Thinness Grade 2 & 0.8 & & 0.5 & & 0.7 & & 0.6 & & 0.7 & & 0.7 & & 0.6 & \\
\hline Thinness Grade 1 & 4.5 & & 5.0 & & 3.7 & & 4.5 & & 4.1 & & 4.5 & & 4.2 & \\
\hline Normal & 74.9 & & 76.1 & & 76.0 & & 74.7 & & 77.4 & & 75.6 & & 76.5 & \\
\hline Overweight & 14.9 & & 14.6 & & 14.9 & & 15.7 & & 13.9 & & 15.0 & & 14.6 & \\
\hline Obese & 4.6 & & 3.6 & & 4.3 & & 4.3 & & 3.7 & & 4.2 & & 3.8 & \\
\hline Waist circumference (cm) & 73.1 & 0.7 & 73.0 & 8.5 & 72.1 & 9.2 & 72.7 & 8.9 & 72.3 & 8.8 & 73.6 & 9.3 & 71.4 & 8.3 \\
\hline $\begin{array}{l}\text { High waist circumference (Canada } \\
\text { classification) }\end{array}$ & 13.4 & & 13.2 & & 11.1 & & 12.3 & & 11.7 & & 14.9 & & 9.0 & \\
\hline \multicolumn{15}{|l|}{ Eating behaviour disorders (EAT-40) } \\
\hline Low risk $(<17.5 / 100)$ & 81.3 & & 81.2 & & 82.3 & & 81.4 & & 82.2 & & 82.1 & & 81.5 & \\
\hline Moderate risk (17.5/100 - 30/100) & 9.9 & & 9.8 & & 10.1 & & 9.9 & & 9.9 & & 9.2 & & 10.7 & \\
\hline High risk $(\geq 30 / 100)$ & 8.8 & & 9.0 & & 7.6 & & 8.7 & & 7.9 & & 8.7 & & 7.8 & \\
\hline \multicolumn{15}{|l|}{$\begin{array}{l}\text { Hospital Anxiety and Depression (HAD } \\
\text { scale) }\end{array}$} \\
\hline High anxiety score $(\geq 50 / 100)$ & 23.3 & & 23.8 & & 24.3 & & 24.4 & & 23.7 & & 22.5 & & 25.7 & \\
\hline High depression score $(\geq 50 / 100)$ & 3.2 & & 2.8 & & 2.5 & & 2.8 & & 2.6 & & 2.6 & & 2.7 & \\
\hline \multicolumn{15}{|l|}{ Duke Health Profile } \\
\hline Physical score $(0-100)$ & 75.4 & 0.5 & 75.1 & 18.9 & 75.6 & 18.5 & 75.3 & 18.6 & 75.5 & 18.7 & 76.1 & 18.6 & 74.6 & 18.7 \\
\hline Mental score $(0-100)$ & 64.4 & 0.6 & 64.8 & 23.4 & 63.9 & 23.3 & 64.0 & 23.6 & 64.7 & 23.1 & 65.1 & 23.1 & 63.5 & 23.6 \\
\hline Social score $(0-100)$ & 68.8 & 0.4 & 68.7 & 19.2 & 68.6 & 19.3 & 68.5 & 19.4 & 68.8 & 19.1 & 68.9 & 19.1 & 68.4 & 19.4 \\
\hline
\end{tabular}

I Overall baseline characteristic parameters are estimated according to stratification and cluster design

* Data are mean when SD is displayed or percentages

** Standard Error of the Mean

$¥$ Standard Deviation

other family members' food choices and needs met [42]. This behaviour is one of the reasons why we chose a school-based intervention as opposed to family or community interventions. Another reason was that educational skills of professional teachers should increase the effectiveness of lessons introduced into the curriculum. The school has been described as an ideal place to run prevention interventions considered an integral part of the educational mission in France [43], as well as internationally $[5,44]$, and to avoid known financial barriers in prevention access.

In terms of national and regional academic programs, schools are free to choose the form in which they provide education for their students, and nutritional education programs such as that in the PRALIMAP trial are used in many French schools without the need to obtain parental consent. Moreover, schools modify their environment on their own. Parental consent is required not for the intervention per se but for the outcomes measurements. Although schools were randomly assigned without consent from adolescents and their parents, both groups received information and could decline to participate in completing questionnaires and measuring body size. Information, access to data and the right to withdraw participation is warranted by French law after approval by adequate committees. 
Summerbell et al. reported that studies focusing on the combination of dietary and physical activity did not show a significant improvement in BMI but that some studies focusing on dietary or physical activity alone showed a small but positive impact on BMI status; however, nearly all studies found some improvement in diet or physical activity behaviour [3]. In contrast, Sharma et al. showed that interventions targeting both physical activity and dietary behaviour were successful in influencing adiposity indices [36]. The PRALIMAP trial aims to focus on both diet and physical activity (as part of an integrative nutritional approach) in each of the 3 strategies.

Nutritional education has been evaluated in adolescents in a few studies with varying design and effectiveness $[2,35,45]$. A systematic review of published and "grey" literature [35] reported a moderate effect in adolescents 13-18 years of age. However, most of these interventions were classroom-based activities with an adapted curriculum. The PRALIMAP trial involves lectures in a quantity corresponding to the median yearly number of hours devoted to this task in other countries [6] but also experiments with other kinds of education through autonomous collaborative works and nutritional parties. These activities may lead to better motivation in students, thanks to a more convivial, pleasant and positive approach to nutrition and to skills acquisition and empowerment.

The PRALIMAP screening strategy is a new concept of school-based screening combining school-based measurements of BMI associated with waist circumference to define overweight and obesity and school-based care. At the onset of the trial, this new approach aroused debates among high school professionals who considered that the high school should not be viewed as a place for health care and among health professionals who are not well trained in proactive strategies of health problems management, being more comfortable with subjects contacting them directly with a care demand. However, Kubik et al. [46] described schools as a setting for obesity prevention (primary and secondary) and particularly highlighted the school nurses' responsibilities as vital but underutilized in delivering school-based obesity prevention. Moreover, the American Institute of Medicine recommended in 2005 to measure BMI in school and to report the results to parents [5]. Some schoolbased screening programs, practice, and effectiveness have been evaluated, and guidance has been provided for implementing such an approach $[6,12,47]$.

In the PRALIMAP trial, waist circumference is associated with BMI to determine overweight and obesity because this measurement is convenient, simple to measure, and correlated with BMI, an approximate index of total body fat, and can be used for longitudinal assessment in management $[44,48]$. The measurement allows for avoiding false positives among athletic students in specific "sports and study" programs.

The proposed care of the PRALIMAP relies on the therapeutic education concepts in a stepwise collective approach that split up the intervention into several stages delivered by a multidisciplinary team, as recommended by the US Preventive Services Task Force [49]. Behavioural interventions were reported as probably safe in children 4-18 years of age and can be effective [50]. Barton et al. [49] showed that low-intensity interventions may be feasible for primary care but did not demonstrate a significant consistent benefit with regard to BMI. However, evidence is still insufficient because of the limited number and sample size of available studies. In the PRALIMAP trial, the intensity of the intervention is low (10-14 hours), but weight outcomes are long term and the number of subjects is high.

The environmental strategy implies reconsideration of high school nutrition policy and functioning, which can be difficult for school staff. However, since 2007, such strategies must be undertaken in French schools with regard to the new recommendations for catering [51]. Moreover, high schools implementing the environmental strategy were specially funded by the Regional Council to help them improve dietary and physical activity school facilities and offerings. Only a few studies have evaluated school nutritional environment interventions, but none showed conclusive results in terms of adolescents' body size, and one found a positive long-term effect on only dietary behaviour $[2,35,35,45,52]$. In the PRALIMAP environmental strategy, a new tool was used to help catering staff improve meals by use of special software that allowed for observing food consumption every day and better adapting the offerings for students, especially for fruits and vegetables [53].

The environmental strategy features an annual nutritional party, but its objectives differ from those of the education strategy party. In the environmental strategy, the party aims to help students discover new foods and physical activities to let them diversify their energy intake and expenditure, whereas the educational strategy party is a pedagogic way to evaluate and improve knowledge.

Multicomponent interventions promoting a healthy diet have been evaluated in high school-aged adolescents in European Union countries. These interventions were of limited effectiveness for self-reported dietary behaviour, and only one included anthropometric measurements, and results were inconclusive [35]. Eating patterns are more likely to improve when changes in the school environment are integrated with classroom nutrition education [54]. "Making healthy choices easier" is a strong recommendation for combining both strategies 
and needs to be evidenced [55]. In fact, no study has assessed the effects of environment and education strategies and their interaction. Because of its factorial design, PRALIMAP allows for determining an interaction between strategies and thus could provide information on an expected greater effectiveness of the combination of consistent educational and environmental strategies. Moreover, it allows for investigating a higher order interaction with the screening strategy. The combination of the 3 strategies could gather all conditions that could contribute to improving the prevention of overweight and obesity.

The PRALIMAP is a pragmatic trial where interventions were implemented in the real context of high schools. Effectiveness [56] is evaluated through body composition measurements, nutritional behaviour and knowledge outcomes, as was recommended by some authors [35,45,57]. The PRALIMAP outcomes rely on anthropometric data collected by high school nurses and on self-reported measures such as knowledge and behaviours collected in the classroom setting. At baseline, we achieved a high participation rate for both types of measurements (85.7\%). The availability of the Board of Education database allows for comparison of the sociodemographic differences between participants and non-participants and suggests a probable higher nonparticipation rate among overweight students. However, non-participation in the PRALIMAP measurements is similar across arms. The turnover with entry level and attrition at each grade is common in schools and is likely to reduce power and even introduce bias if these data differ by randomisation arm. The design offers the opportunity to analyse the data in a longitudinal cohort approach, as well as in a repeated cross sectional approach. It offers the opportunity to combine hard outcomes (body size) with declared and perceived outcomes [58] (self-administered questionnaires) to explore the hypothetical cause from knowledge to health. Questionnaires used were standardised internationally or specifically designed for PRALIMAP. The time interval between the second and last visit measurements was shorter in the vocational than general and technological high schools, but the stratification design allowed us to control for this difference.

A remarkable feature of the PRALIMAP is the extensive and comprehensive process evaluation. The trial was designed to investigate not only the outcomes relating to nutritional behaviours but also the processes involved in developing and implementing the intervention strategies, as well as the type of nutritional activities provided in the control schools for each strategy. This feature can help interpret observed relationships between the interventions and outcomes. A specific work is planned to provide an estimation of the dose of intervention, which will allow for more intensive analysis beyond a simple interpretation task by performing a per protocol statistical analysis including the dose of each strategy implemented in each high school.

In conclusion, the PRALIMAP trial aims to improve the prevention and management of overweight and obesity in adolescents by translating current evidence into public health practice. For almost 10 years, the French government has implemented a concerted nationwide strategy to reduce the prevalence of obesity at every age. Determining the most effective strategies to implement guidelines in schools is a major component of this program, which needs to be more successful in meeting the needs of subjects, particularly those from lower socioeconomic classes [59]. The results should inform how best to implement effective nutrition prevention programs in a school environment targeting adolescents at a time in their lives when they develop responsibilities and empowerment for health attitude behaviours. The initial results are expected in late 2010.

\section{Additional material}

Additional file 1: ICC1: Intra-class correlation coefficient estimates without taking into account the stratification for high school administrative area department and type.

Additional file 2: ICC2: Intra-class correlation coefficient estimates taking into account the stratification for high school administrative area department and type.

\section{Acknowledgements}

Many people worked together selflessly and enthusiastically to make the PRALIMAP trial a success. The PRALIMAP trial group warmly acknowledges the students and their parents who participated in the measurements and interventions and the high school professionals (nurses, teachers, administrative staff, headmasters and catering staff) who contributed to the recruitment of students and delivery of the interventions. Participating high schools are Albert Schweitzer High School, Bitche; Emile Levassor High School, Dombasle-Sur-Meurthe; Pierre Mendès France High School, Epinal; Ernest Bichat High School, Lunéville; Jeanne D’Arc High School, Nancy; JeanVictor Poncelet High School, Saint-Avold; Alfred Kastler High School, Stenay; Helene Boucher High School, Thionville; Raymond Poincare High School, Bar-le-Duc; Louis Bertrand High School, Briey; Henri Vogt High School, Commercy; Charles Hermite High School, Dieuze; Darche High School; Longwy; Georges De La Tour High School, Metz; Pierre et Marie Curie High School, Neufchâteau; Jean Hanzelet High School, Pont-A-Mousson; Camille Claudel High School, Remiremont; Julie Daubié High School, Rombas; Jules Ferry High School, Saint-Dié-des-Vosges; Mangin High School, Sarrebourg; Henri Nominé High School, Sarreguemines; Louis Majorelle High School, Toul; Jacque Callot High School, Vandoeuvre-lès-Nancy; Alain Fournier High School, Verdun.

We warmly thank Stéphane THOMAS and his statistical team of Nancy-Metz Academy Board of Education for making available the required student database.

We are grateful to all PRALIMAP monitors working in the Regional institute for health education (IREPS) for implementing educational and environmental strategies in the high schools and for contributing to data collection.

We acknowledge the contribution of Drs. Gilles ROBERT and François KURTZ and Pr. Olivier ZIEGLER and their health professional networks, as well as Dr. Michel HELFENSTEIN and the mobile team of the Centre de Médecine 
Préventive of Vandoeuvre-lès-Nancy, and finally Joelle LIGHEZZOLO and Elisabeth SPITZ and their health psychologists team for contributing to the definition and implementation of the therapeutic education session for overweight and obese adolescents in high schools receiving the screening strategy.

We thank ADEPS for physical activity interventions and Daniel MASLANKA for implementing VEGETAL TONIC ${ }^{\circledR}$ in high schools receiving the environmental strategy.

We thank all administrative and technical staff of the Nancy National conservatory of arts and crafts (CNAM), the Nancy School of Public Health, the Nancy-University EA 4360 Apemac team and the epidemiology and clinical evaluation department of the Nancy-University Hospital for their contribution to data collection, keyboarding, data management, activity reporting, and logistic and financial management.

The PRALIMAP steering committee consists of Evelyne APTEL, Noémie ANGEL, Raphaëlle ANCELLIN, Françoise BAILLY, Lucette BARTHELEMY, Daouia BEZAZ, Serge BRIANCON, Jean-François COLLIN, Rozenn De LAVENNE, Evelyne DIETZ, Pascal ENRIETTO, Elisabeth FAVRE, Magali GENTIEU, Emmanuel GOUAULT, Michel HELFENSTEIN, Serge HERCBERG, François KURTZ, Patrick LAURE, Edith LECOMTE, Joëlle LIGHEZZOLO, Patrick MARX, Aline OSBERY, Marie-Odile PIQUEE, Pierre RENAUDIN, Gilles ROBERT, Anne SCHICHTEL, Anne VUILLEMIN, Elisabeth VILLEMIN, Mireille WUILLAUME.

The PRALIMAP trial received support from public and private sectors. Special acknowledgements are addressed to ARH Lorraine, Conseil Régional de Lorraine, DRASS de Lorraine, GRSP de Lorraine, Fondation Cœurs et Artères, Fondation Wyeth, Ministère de l'enseignement supérieur et de la recherche, Inca, IRESP, Régime local d'assurance maladie d'Alsace Lorraine and Urcam de Lorraine. All trial steps, design, data collection, analysis, write-up, and reports are and will be performed independently of any funding or sponsoring agency.

\section{Author details}

${ }^{1}$ Nancy-University, Paul Verlaine Metz University, Paris Descartes University, EA4360 Apemac, Nancy, France. ${ }^{2}$ Nancy-University, Faculty of medicine, School of Public Health, Nancy, France. ${ }^{3}$ Nancy University Hospital, Epidemiology and clinical evaluation department, Nancy, France. ${ }^{4}$ UMR U557 INSERM/U1125 Inra/CNAM/Paris 13, SBMH-Paris 13 University, Bobigny, France. ${ }^{5}$ National conservatory of arts and crafts (CNAM), Nancy, France. ${ }^{6}$ Local school office of the Nancy-Metz academy, Nancy, France. ${ }^{7}$ Regional institute for health education (IREPS), Nancy, France.

\section{Authors' contributions}

$\mathrm{SB}$ is the principal investigator for the PRALIMAP trial. JFC is the coinvestigator. NA, EB, SB and ST are outcomes evaluation and statistical managers. EB, JFC and $K L$ are the process evaluation managers. NA, EB, SB and ST drafted the manuscript. EL is logistic head managers and EA is high school professional head managers. All authors read and approved the final manuscript. SB is the paper guarantor. PRALIMAP trial group consisted of EA, $E B, S B, E L$ and, $L B, C G, A O$ and $R D L$. It has the power to make all strategic decisions and assures the cooperation between investigator teams and between field and investigator teams.

\section{Competing interests}

The authors declare that they have no competing interests.

Received: 16 June 2010 Accepted: 6 December 2010 Published: 6 December 2010

\section{References}

1. Wang LY, Chyen D, Lee S, Lowry R: The association between body mass index in adolescence and obesity in adulthood. J Adolesc Health 2008, 42:512-518.

2. Doak CM, Visscher TL, Renders CM, Seidell JC: The prevention of overweight and obesity in children and adolescents: a review of interventions and programmes. Obes Rev 2006, 7:111-136.

3. Summerbell CD, Waters E, Edmunds LD, Kelly S, Brown T, Campbell KJ: Interventions for preventing obesity in children. Cochrane Database Syst Rev 2005, CD001871.

4. Doak C, Heitmann BL, Summerbell C, Lissner L: Prevention of childhood obesity - what type of evidence should we consider relevant? Obes Rev 2009, 10:350-356.
5. Institute of Medicine: Preventing Childhood Obesity: Health in the Balance Washington DC: National Academies Press; 2005.

6. Story M, Nanney MS, Schwartz MB: Schools and obesity prevention: creating school environments and policies to promote healthy eating and physical activity. Milbank Q 2009, 87:71-100.

7. World Health Organization: The Ottawa Charter for Health Promotion. Milestones in Health Promotion. Statements from Global Conferences World Health Organization (dir. pub.). Switzerland: World Health Organisation Press; 2009, 1-5.

8. Hercberg S, Chat-Yung S, Chauliac M: The French National Nutrition and Health Program: 2001-2006-2010. Int J Public Health 2008, 53:68-77.

9. Cole TJ, Flegal KM, Nicholls D, Jackson AA: Body mass index cut offs to define thinness in children and adolescents: international survey. BMJ 2007, 335:194

10. Cole TJ, Bellizzi MC, Flegal KM, Dietz WH: Establishing a standard definition for child overweight and obesity worldwide: international survey. BMJ 2000, 320:1240-1243.

11. McCarthy HD, Jarrett KV, Crawley HF: The development of waist circumference percentiles in British children aged 5.0-16.9 y. Eur J Clin Nutr 2001, 55:902-907.

12. Nihiser AJ, Lee SM, Wechsler H, McKenna M, Odom E, Reinold C, Thompson D, Grummer-Strawn L: Body mass index measurement in schools. J Sch Health 2007, 77:651-671.

13. Rolland-Cachera MF, Cole TJ, Sempe M, Tichet J, Rossignol C, Charraud A: Body Mass Index variations: centiles from birth to 87 years. Eur J Clin Nutr 1991, 45:13-21.

14. Katzmarzyk PT: Waist circumference percentiles for Canadian youth 11-18 y of age. Eur J Clin Nutr 2004, 58:1011-1015.

15. Lean ME, Han TS, Morrison CE: Waist circumference as a measure for indicating need for weight management. BMJ 1995, 311:158-161.

16. Craig $C L$, Marshall AL, Sjostrom M, Bauman AE, Booth ML, Ainsworth BE, Pratt M, Ekelund U, Yngve A, Sallis JF, et al: International physical activity questionnaire: 12-country reliability and validity. Med Sci Sports Exerc 2003, 35:1381-1395.

17. Garner DM, Garfinkel PE: The Eating Attitudes Test: an index of the symptoms of anorexia nervosa. Psychol Med 1979, 9:273-279.

18. Garner DM, Olmsted MP, Bohr Y, Garfinkel PE: The eating attitudes test: psychometric features and clinical correlates. Psychol Med 1982, 12:871-878.

19. Zigmond AS, Snaith RP: The hospital anxiety and depression scale. Acta Psychiatr Scand 1983, 67:361-370.

20. Lepine JP, Godchau M, Brun P: Anxiety and depression in inpatients. Lancet 1985, 2:1425-1426.

21. Lisspers J, Nygren A, Soderman E: Hospital Anxiety and Depression Scale (HAD): some psychometric data for a Swedish sample. Acta Psychiatr Scand 1997, 96:281-286.

22. Parkerson GR Jr, Broadhead WE, Tse CK: The Duke Health Profile. A 17item measure of health and dysfunction. Med Care 1990, 28:1056-1072.

23. Vo TX, Guillemin F, Deschamps JP: Psychometric properties of the DUKE Health Profile-adolescent version (DHP-A): a generic instrument for adolescents. Qual Life Res 2005, 14:2229-2234.

24. Kubik MY, Lytle L, Fulkerson JA: Physical activity, dietary practices, and other health behaviors of at-risk youth attending alternative high schools. J Sch Health 2004, 74:119-124.

25. Grunbaum JA, Lowry R, Kann L: Prevalence of health-related behaviors among alternative high school students as compared with students attending regular high schools. J Adolesc Health 2001, 29:337-343.

26. Calderon LL, Yu CK, Jambazian P: Dieting practices in high school students. J Am Diet Assoc 2004, 104:1369-1374.

27. Elbourne DR, Campbell MK: Extending the CONSORT statement to cluster randomized trials: for discussion. Stat Med 2001, 20:489-496.

28. Campbell MK, Elbourne DR, Altman DG: CONSORT statement: extension to cluster randomised trials. BMJ 2004, 328:702-708.

29. Les élèves du second degré. In Repères et références statistiques sur les enseignements, la formation et la recherche. Edited by: Vitry D (dir. pub.). Paris: Le ministère de l'Éducation nationale et le ministère de l'Enseignement supérieur et de la Recherche; 2009:91-146.

30. Brownson RC, Fielding JE, Maylahn CM: Evidence-based public health: a fundamental concept for public health practice. Annu Rev Public Health 2009, 30:175-201. 
31. Donner A, Klar N: Design and Analysis of Cluster Randomization Trials in Health Research London: Arnold; 2000.

32. Hays RJ, Moulton LH: Cluster randomised trials Boca Raton, FL, USA: CRC press; 2009.

33. Hopewell S, Dutton S, Yu LM, Chan AW, Altman DG: The quality of reports of randomised trials in 2000 and 2006: comparative study of articles indexed in PubMed. BMJ 2010, 340:c723.

34. Abernethy AP, Currow DC, Hunt R, Williams H, Roder-Allen G, Rowett D, Shelby-James T, Esterman A, May F, Phillips PA: A pragmatic $2 \times 2 \times 2$ factorial cluster randomized controlled trial of educational outreach visiting and case conferencing in palliative care-methodology of the Palliative Care Trial [ISRCTN 81117481]. Contemp Clin Trials 2006, 27:83-100.

35. Van Cauwenberghe E, Maes L, Spittaels H, van Lenthe FJ, Brug J, Oppert JM De Bl: Effectiveness of school-based interventions in Europe to promote healthy nutrition in children and adolescents: systematic review of published and 'grey' literature. Br J Nutr 2010, 103:781-797.

36. Sharma M: Behavioural interventions for preventing and treating obesity in adults. Obes Rev 2007, 8:441-449.

37. Milligan RA, Burke V, Beilin LJ, Richards J, Dunbar D, Spencer M, Balde E, Gracey MP: Health-related behaviours and psycho-social characteristics of 18 year-old Australians. Soc Sci Med 1997, 45:1549-1562.

38. Neumark-Sztainer D, Story M, Perry C, Casey MA: Factors influencing food choices of adolescents: findings from focus-group discussions with adolescents. J Am Diet Assoc 1999, 99:929-937.

39. Videon TM, Manning CK: Influences on adolescent eating patterns: the importance of family meals. J Adolesc Health 2003, 32:365-373.

40. Contento IR, Koch PA, Lee H, Sauberli W, Calabrese-Barton A: Enhancing personal agency and competence in eating and moving: formative evaluation of a middle school curriculum-Choice, Control, and Change. J Nutr Educ Behav 2007, 39:S179-S186.

41. Hill AJ: Developmental issues in attitudes to food and diet. Proc Nutr SoC 2002, 61:259-266.

42. Contento IR, Williams SS, Michela JL, Franklin AB: Understanding the food choice process of adolescents in the context of family and friends. $J$ Adolesc Health 2006, 38:575-582.

43. Prévention des conduites à risque et comité d'éducation à la santé et à la citoyenneté. Circulaire 98-108, 1-7-1998. BO n²8. 1998.

44. World Health Organization: Obesity: preventing and managing the global epidemic Geneva, Switzerland; 2000.

45. De Bourdeaudhuij I, Van Cauwenberghe E, Spittaels H, Oppert JM, Rostami C, Brug J, Van Lenthe F, Lobstein T, Maes L: School-based interventions promoting both physical activity and healthy eating in Europe: a systematic review within the HOPE project. Obes Rev 2010.

46. Kubik MY, Story M, Davey C: Obesity prevention in schools: current role and future practice of school nurses. Prev Med 2007, 44:504-507.

47. Nihiser AJ, Lee SM, Wechsler H, McKenna M, Odom E, Reinold C, Thompson D, Grummer-Strawn L: BMI measurement in schools. Pediatrics 2009, 124(Suppl 1):S89-S97.

48. National Health and Medical Research Council: Clinical practice guidelines for the management of overweight and obesity in children and adolescents. National Health and Medical Research Council. phd publication; 2003, 1-138.

49. Barton M: Screening for obesity in children and adolescents: US Preventive Services Task Force recommendation statement. Pediatrics 2010, 125:361-367

50. Whitlock EP, O'Connor EA, Williams SB, Beil TL, Lutz KW: Effectiveness of weight management interventions in children: a targeted systematic review for the USPSTF. Pediatrics 2010, 125:e396-e418.

51. Groupe d'Etude des Marchés de Restauration Collective et de Nutrition: RECOMMANDATION RELATIVE A LA NUTRITION. Paris 2007.

52. Story $M$, Hayes $M$, Kalina $B$ : Availability of foods in high schools: is there cause for concern? J Am Diet Assoc 1996, 96:123-126.

53. Vegetal Tonic. [http://www.apasp.com/modules/movie/scenes/home/index. php?fuseAction=show\&rubric=leftMenuArticles\&article=vegetaltonic].

54. Lytle LA, David MM, Cheryl LP, Mary S, Amanda S Birnbaum, Martha YK: School-based approaches to affect adolescents' diets: results from the TEENS study. Health education \& behavior: the official publication of the Society for Public Health Education 2004, 31:270-287.

55. Department of Health: Choosing health: making healthy choices easier. London 2005.
56. Gartlehner G, Hansen RA, Nissman D, Lohr KN, Carey TS: Criteria for Distinguishing Effectiveness From Efficacy Trials in Systematic Reviews. Rockville, MD: Agency for Healthcare Research and Quality; 2006.

57. O'Brien G, Davies M: Nutrition knowledge and body mass index. Health Educ Res 2007, 22:571-575.

58. Patrick DL: Patient-Reported Outcomes (PROs): an organizing tool for concept, measures and application. Quality of Life News Letter 2003, 1-5.

59. Vernay M, Malon A, Oleko A, Salanave B, Roudier C, Szego E, Deschamps V, Hercberg S, Castetbon K: Association of socioeconomic status with overall overweight and central obesity in men and women: the French Nutrition and Health Survey 2006. BMC Public Health 2009, 9:215.

doi:10.1186/1745-6215-11-119

Cite this article as: Briançon et al:: PRALIMAP: study protocol for a high school-based, factorial cluster randomised interventional trial of three overweight and obesity prevention strategies. Trials 2010 11:119.

\section{Submit your next manuscript to BioMed Central and take full advantage of:}

- Convenient online submission

- Thorough peer review

- No space constraints or color figure charges

- Immediate publication on acceptance

- Inclusion in PubMed, CAS, Scopus and Google Scholar

- Research which is freely available for redistribution

Submit your manuscript at www.biomedcentral.com/submit
Biomed Central 